\title{
ANÁLISIS COMPARADO DE TENDENCIAS SOCIALES Una aplicación al caso de la Comunidad Valenciana
}

\author{
MIGUEL ÁNGEL MATEO PÉREZ
}

Universidad de Alicante

\author{
PALABRAS CLAVE ADICIONALES \\ ADDITIONAL KEYWORDS \\ Análisis longitudinal, Series temporales, \\ Longitudinal Analysis, Temporary Series, \\ Comunidad Valenciana. \\ Valencian Region.
}

RESUMEN. El análisis longitudinal de datos es una manera de describir y explicar los procesos sociales. Dependiendo de la fuente de los datos se pueden establecer ciclos estadísticos y ciclos de opinión pública. Este artículo propone la comparación entre ambos tipos de ciclos para la Comunidad Valenciana entre 1977 y 1997. Se concluye con una reflexión sobre la pertinencia de la inclusión de la perspectiva longitudinal en el análisis de la realidad social.

\section{INTRODUCCIÓN}

Desde hace ya bastante tiempo se ha venido utilizando la teoría de los ciclos para explicar diferentes procesos sociales. Quizá los más conocidos sean los llamados ciclos económicos estudiados desde muy diversas perspectivas (Kondratiev, 1979; Mandel, 1986; Schumpeter, 1939 y 1982; Fontela, 1997; Amin, 1997 y últimamente y desde la perspectiva del crecimiento: Evans, 1998; Epstein, 1999), pero no faltan estudios en los que se pone la tilde en otros aspectos, como los demográficos (De Miguel, 1986) o los políticos (Moscoso y Babiano, 1992 y

Revista Internacional de Sociología (RIS)

Tercera Época, nº 25, Enero-Abril, 2000, pp. 121-147. 
más recientemente Reid,1998 y Sapir, Sekkat, 1999). Intentos más novedosos son más raros en la literatura especializada, aunque se echa en falta el establecimiento de los principios fundamentales de lo que podrían ser ciclos de protección social, por ejemplo.

Los ciclos los podemos utilizar desde varios puntos de vista: como un fin en sí mismo, como una forma de presentación de los resultados de una serie de datos (desde criterios longitudinales) o como (esta última es bastante más discutible) un elemento explicativo de otros procesos. Aunque la última es la más comprometida y difícil en su justificación, es probablemente la más interesante.

Los ciclos, entendidos como un fin en sí mismos, se comprenden si atendemos a las diferentes propuestas de la teoría de los ciclos económicos: crecimiento y decrecimiento de la economía en términos generales, desde una perspectiva temporal de larga duración, duración temporal media y corta duración. Y no sólo los ciclos de crecimiento y decrecimiento, sino también otros, como los ciclos de innovación, están bajo esta óptica.

Otros tipos de ciclos los podemos obtener cuando presentamos de manera longitudinal una serie temporal de datos estadísticos (nunca con datos absolutos, sino con variaciones). El análisis de los datos longitudinales está bastante bien desarrollado, también desde la econometría, quizá porque los datos con los que trabajan los econometras permitan, como veremos, determinados análisis que en otros procesos sociales serían ilusorios precisamente por la propia naturaleza de los datos sociales.

Podemos ir un poco más allá cuando hablamos de tendencias, ciclos y análisis longitudinal. Supongamos dos procesos sociales tomados de manera longitudinal (desarrollo económico de España desde 1970 hasta 1999 y las hectáreas deforestadas también en dicho periodo) y queremos establecer si existe relación entre un proceso y otro. Mediante análisis paramétrico podemos concluir que existe una correlación estadística entre los dos fenómenos, pero podemos afinar un poco más sometiendo los resultados estadísticos al análisis sociológico y observando que allí donde hay evidencia en cuanto asociación estadística no tiene por qué ser también sociológica.

Dicho de otra manera, si las oscilaciones del PIB nos muestran los signos del ciclo económico, y dichas oscilaciones correlacionan perfectamente con la incorporación de la mujer al trabajo asalariado, podemos llegar a pensar que lo último es factor explicativo del primero. Podría ser. Pero si hay algo cierto, es que ambos tipos de datos nos sirven a los sociólogos para la caracterización de la realidad social.

Y es que aunque hoy sigamos pensando en términos lineales (Galtung, 1995) parece claro que la metodología de los ciclos, si se me permite esta expresión, se hace cada vez más necesaria, dado el carácter complejo y multidireccional de los procesos sociales. Y es precisamente en la disciplina de la economía donde la perspectiva cíclica ha tenido una mayor repercusión y escuela. La teoría de los 
ciclos económicos (en la que no vamos a entrar aquí de forma extensa) nos señala que, independientemente del ámbito temporal que determinemos, se sucede con una regularidad más o menos estable una alternancia de estados.

En las páginas que siguen proponemos dos cosas. En primer lugar, que los ciclos económicos (estadísticos, fundamentalmente) establecidos para España y la Comunidad Valenciana desde 1980 hasta nuestros días, ofrecen al compararlos con otro tipo de ciclos, los de opinión pública precisamente sobre la situación general y económica de la propia Comunidad Autónoma, una fuente complementaria para el conocimiento de la realidad social; en segundo lugar, establecemos algunas de las conexiones entre los diferentes tipos de ciclos (o tendencias, que más tarde tendremos oportunidad de discutir). Pero antes se expondrán algunas notas metodológicas para cada tipo de ciclo.

\section{NOTAS METODOLÓGICAS}

En la investigación social podemos (o mejor, debemos) trabajar con distintos tipos de datos. No sólo los datos producidos por nosotros mismos (datos primarios) son los básicos para el conocimiento de la realidad social. Imaginemos que planteamos un estudio complejo sobre las relaciones existentes entre la violencia infantil y los medios de comunicación. Realizamos un diseño metodológico impecable, una recogida de datos mediante cuestionario y una análisis paramétrico obteniendo los resultados esperados. Y descubrimos la existencia de otro estudio que no sólo está realizado en mejores condiciones que el nuestro (más muestra, más medios, mejor instrumento de recogida de datos), sino que no hemos utilizado los resultados que vertía, y que prácticamente y en función de nuestros objetivos podría haber solucionado una parte de nuestra investigación.

Los datos secundarios, producidos por otras fuentes, generalmente con más medios para la investigación social que el investigador en solitario, son un buen punto de partida para las investigaciones que vamos realizando. Y el análisis riguroso de estos datos producidos por otros es motivo de reflexión y trabajo. Cómo mejorar las fuentes secundarias para el trabajo con indicadores longitudinales, parece una de las necesidades clave en la investigación social empírica.

Los datos secundarios hay que entenderlos dentro de las diferentes perspectivas o metodologías de investigación. Si hacemos caso a L.E. Alonso y definimos el método como "un estadio - y también un estilo- en el acceso al estudio de la realidad social "(Alonso, 1998: 9) los usos que realicemos de los datos, tanto primarios como secundarios, han de estar de acuerdo precisamente con las pautas metodológicas de nuestra investigación. Tipos de metodologías hay suficientes (González,1997) como para complicar estas páginas al máximo. Entre el catálogo de metodologías posibles, podemos destacar, por motivos que enseguida se expondrán, la metodología comparativa. 
Muchas veces, para la realización de nuestros trabajos utilizamos fuentes diferentes, datos producidos y de naturalezas dispares que debemos tratar en su justa medida, es decir, con sus propias ventajas y limitaciones. En nuestro caso, cuando pretendemos comparar datos procedentes de encuestas de opinión pública con datos procedentes de estadísticas (no olvidemos que también son producidos mediante encuesta, pero la base numérica de las mismas, la muestra y otra serie de factores las convierten en datos muchos más fiables y con menos márgenes de error que las meras encuestas de opinión) debemos tener presente una serie de elementos de la metodología comparativa que nos limitan (o potencian) precisamente el análisis comparado (Caïs,1997).

Datos procedentes de estadísticas presentadas desde una perspectiva temporal más o menos amplia, forman, si atendemos a las variaciones relativas, series temporales de datos. El análisis de series temporales tiene como objeto explicar la evolución de una o más variables en el tiempo, estando formadas por componentes regulares y por otros irregulares. La expresión matemática de una serie temporal puede ser:

$$
Y_{t}=T_{1}\left(C_{t}+E\right)_{t} \times i_{t}
$$

Donde:

$$
\begin{aligned}
& Y_{t}=\text { serie temporal en función del tiempo } \\
& T_{t}=\text { tendencia principal } \\
& C_{t}=\text { ciclo } \\
& E_{t}=\text { variación estacional } \\
& i_{t}=\text { componente irregular }
\end{aligned}
$$

Si la construcción de series temporales con datos estadísticos ya tiene sus problemas y sus limitaciones, es razonable que para datos de opinión pública, al reducirse la base numérica (menor número de casos por estudio y por lo tanto por unidad a comparar) y al no disponer por norma general de datos procedentes de panel, la construcción de series temporales en sentido estricto sea casi imposible. A pesar de esto, no podemos quitarle relevancia a un aspecto básico del análisis longitudinal: aunque no podamos establecer series de opinión pública, sí podemos observar con mayor o menor precisión las variaciones cíclicas que a grandes rasgos se van produciendo en las unidades que tomemos como referencia.

Algunas de las limitaciones básicas que tenemos a la hora de hablar de series con datos secundarios de opinión pública las encontramos en la tabla 1. 
Tabla 1.

Limitaciones en la construcción de series de opinión pública.

\begin{tabular}{ll}
\hline \multicolumn{1}{c}{ Cuestión } & \multicolumn{1}{c}{ Implica } \\
\hline $\begin{array}{l}\text { Base temporal irregular } \\
\text { Cambios en la frecuencia }\end{array}$ & $\begin{array}{l}\text { No disposición de series temporales con } \\
\text { base temporal fija }\end{array}$ \\
\hline $\begin{array}{l}\text { Cambios en el número de cuestionarios } \\
\text { realizados } \\
\begin{array}{l}\text { Trabajo con muestras pequeñas (entre 1200 } \\
\text { y 2500 casos) }\end{array}\end{array}$ & $\begin{array}{l}\text { Alteraciones serias en la composición de } \\
\text { la muestra. En sentido estricto, la muestra } \\
\text { no conforma paneles para la comparación }\end{array}$ \\
\hline $\begin{array}{l}\text { Filtros de preguntas } \\
\text { nambios en el cuestionario: }\end{array}$ & $\begin{array}{l}\text { Reducción de la «n» válida hasta } \\
\text { límites en los que el error muestral es } \\
\text { demasiado alto }\end{array}$ \\
$\begin{array}{l}\text { preguntas diferentes, temas distintos, posición } \\
\text { variable de las preguntas en cuestionarios similares, } \\
\text { cambios en las alternativas de respuesta }\end{array}$ & $\begin{array}{l}\text { Alteración en la herramienta de recogida } \\
\text { de datos. Afecta a la fiabilidad de los datos }\end{array}$ \\
\hline
\end{tabular}

\section{LA SITUACIÓN ECONÓMICA EN LA COMUNIDAD VALENCIANA}

Muchos indicadores (tanto macro como microeconómicos) pueden ser tomados para la caracterización de la economía en la Comunidad Valenciana. Vamos a tomar la evolución de la población ocupada (realizaremos un comparativo entre España y la Comunidad Valenciana) y distribución de la ocupación por sectores y datos sobre la creación y destrucción de empleo, y sobre el paro (nacional y de la Comunidad Valenciana). Creemos que esos elementos (con sus limitaciones) pueden ayudarnos a comprender la situación económica de la Comunidad Valenciana de los años 80 y 90 de manera introductoria y observar su evolución en el tiempo. Así pues, aunque la situación económica de la Comunidad Valenciana depende de un gran número de factores que no enumeraremos, podemos sintetizar el significado y el signo de dicha situación en la evolución y características del empleo. También haremos alguna referencia a los ciclos económicos desde los últimos años del franquismo hasta nuestros días. Algunos autores han señalado que, para establecer ciclos económicos, son necesarios los siguientes elementos: 1) variaciones en los niveles de producción; 2) variaciones en el empleo y 3) variaciones en los precios (Conde y González, 1998:37-39). 
Vamos a tomar una perspectiva amplia basada en estos elementos, centrándonos más en la cuestión del empleo (ocupación y paro) que en los temas de producción, por ejemplo. Finalizaremos con una referencia para el caso español de la relación entre empleo e inflacción.

\section{Población ocupada: total y por sectores económicos}

Un primer indicador que podemos tomar para realizar el diagnóstico de la situación económica de la Comunidad Valenciana desde finales del franquismo hasta nuestros días es la población ocupada. En un principio, es sensato pensar que la evolución de la población ocupada tanto para España como para la Comunidad Valenciana debe ser paralela, al menos en tendencias. En números absolutos es imposible la comparación entre la evolución (en miles) de la ocupación en España y en la Comunidad Valenciana. Sí sería posible si trabajásemos con tasas de ocupación. Pero he creído conveniente trabajar con la ocupación en datos absolutos para construir un indicador que relacione el incremento (positivo o negativo) porcentual entre la ocupación de un año y su anterior, tanto para España como para el Comunidad Valenciana.

A la luz de lo representado en el gráfico 1, parece que: 1) las diferencias entre los incrementos (positivos o negativos) en las dos series no parecen tan significativos para que pudiéramos concluir que existe una disociación entre España y la Comunidad Valenciana en cuanto a la evolución de la población ocupada; y 2) con la mencionada evolución podemos observar con cierta claridad distintas etapas en la población ocupada, diferenciadas por el signo del incremento. Lo más que podríamos señalar, además de los periodos claros de incremento de la ocupación y descenso de la misma casi de manera cíclica, es que parece que la Comunidad Valenciana (línea más gruesa en el gráfico anterior) sufre cierto retraso con respecto a la variación nacional aproximadamente de un año. Esto que podría ser explicado, pero en lo que no me detendré, tiene bastante relevancia desde el punto de vista del impacto de las políticas económicas supuestamente generadoras de empleo.

Es importante que, al margen de la observación cuidadosa de las evoluciones paralelas de la ocupación absoluta, nos detengamos brevemente en la ocupación por sectores económicos. Aunque la terminología y clasificación de los sectores económicos es bastante conocida, parece claro que muchas de las actividades que se realizan desde un punto de vista económico y que reportan beneficios en forma de dinero, son difícilmente clasificables en un solo grupo. Al margen de la economía formal o informal, los sectores de ocupación que agrupan las principales actividades serían: a) sector primario, en el que la agricultura y otras actividades extractivas predominan; b) sector secundario, en el que se encuadran las actividades de transformación (industriales); c) sector terciario, en el que encontramos las actividades encuadradas en los servicios. Desde el punto de vista del 
Gráfico 1.

Evolución de los incrementos anuales (\%) de la ocupación.

España, Comunidad Valenciana.

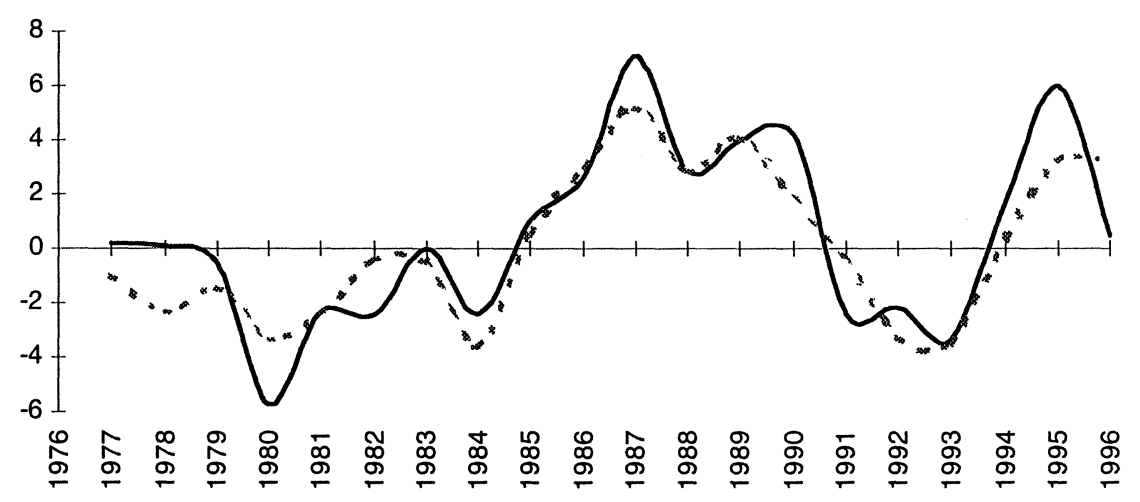

hcrem C.V. $* \cdots$ - hcrem ESP

INE, se clasifican las ocupaciones en el llamado CNO de ocupaciones. Estas ocupaciones (o profesiones) se sistematizan por ramas de actividad en el CNAE, cuya estructura (de 5 dígitos) hace posible la clasificación por ramas de actividad hasta las más impensadas ocupaciones.

Algunos autores (Bell,1973) hablan de un sector cuaternario de servicios hiperespecializados que se corresponde con las actividades básicas de la sociedad posindustrial. Otros autores (Beneyto, 1992) separan la construcción como un sector intermedio entre el secundario y el terciario. Especialmente para la Comunidad Valenciana es bastante interesante realizar la división entre primario, secundario, construcción y terciario, por el peso específico que el sector de la construcción ha tenido y tiene en la economía valenciana al emplear un importante volumen de población. La evolución del \% de ocupados por sectores económicos desde 1977 hasta 1991 y para la Comunidad Valenciana, lo puede encontrar el lector en la tabla 2.

A la luz de estos datos para la Comunidad Valenciana, se puede decir que se ha producido el clásico trasvase de población entre los sectores que definen los sistemas productivos considerados como "modernos". Descenso del $50 \%$ en la agricultura, descenso más paulatino en la industria y un inflamiento del sector servicios. Esto, al margen de ser alabado por los partidarios de la "modernización" esconde tras de sí algunas cuestiones que paso a comentar brevemente. Aunque el peso aparente de los dos primeros sectores ha ido bajando en el total, es posible decir que mucho del trabajo que proporciona la economía sumergida 
Tabla 2.

Evolución de la población ocupada por sectores en la Comunidad Valenciana (\%).

\begin{tabular}{lccccc}
\hline Años & Primario & Secundario & Construcción & Terciario & Total \\
\hline 1977 & 16,5 & 35 & 9,2 & 39,3 & 100 \\
1981 & 13,6 & 32,5 & 7,2 & 46,7 & 100 \\
1985 & 13,5 & 29,1 & 6,5 & 50,9 & 100 \\
1991 & 7,5 & 27,5 & 9,5 & 55,5 & 100 \\
\hline
\end{tabular}

Fuente: INE-EPA.

está en estos sectores: colectivos inmigrantes trabajando en el campo (evidentemente, eso no se computa),y fábricas clandestinas en el sector industrial del calzado y que muchas veces son el putting out system en pleno siglo XXI, calco de las sociedades preindustriales. Las fluctuaciones en el sector de la construcción son también relativamente importantes. De tener ocupado a un $9,2 \%$ de la población en 1977 pasa a tener un 6,5\% en 1985 (en menos de 10 años). También es de suponer que esta crisis en la construcción está ligada de igual manera a la crisis económica más general, y, en particular, a la crisis del turismo. Sin embargo, el incremento paulatino de la población ocupada en los servicios (hasta llegar al $60 \%$ en nuestros días) es también explicable dentro del conjunto de la economía nacional y europea. Pero antes de continuar, una pequeña consideración: ¿existe alguna relación entre el incremento del sector terciario y la precarización del empleo en términos generales?. Probablemente así sea, pero eso lo dejamos para otros estudios.

\section{El paro como indicador de crisis económicas}

Ahora vamos a utilizar otro indicador económico para tratar de establecer el signo de la economía valenciana desde el fin del franquismo. El indicador del que vamos a tratar en las siguientes páginas es el paro. Parece aceptado por todos que la situación económica idílica es la de pleno empleo, o la de ausencia total de paro. Esta situación es bastante rara en condiciones económicas normales. $\mathrm{Ni}$ siquiera el franquismo, con su discurso de pleno empleo, lo consiguió. La explicación de esto nos llevaría a otros asuntos que no trataremos. Lo que sí nos parece relevante y así se señala, es que incrementos rápidos y continuados del paro tienen un efecto claro sobre el signo económico del momento. Situaciones de un gran volumen de paro (o de rápido incremento de éste) se asocian a fases depresivas de la economía. Si además coinciden con un descenso generalizado 
Gráfico 2.

Evolución de la población ocupada por sectores. Comunidad Valenciana (1977-1991)

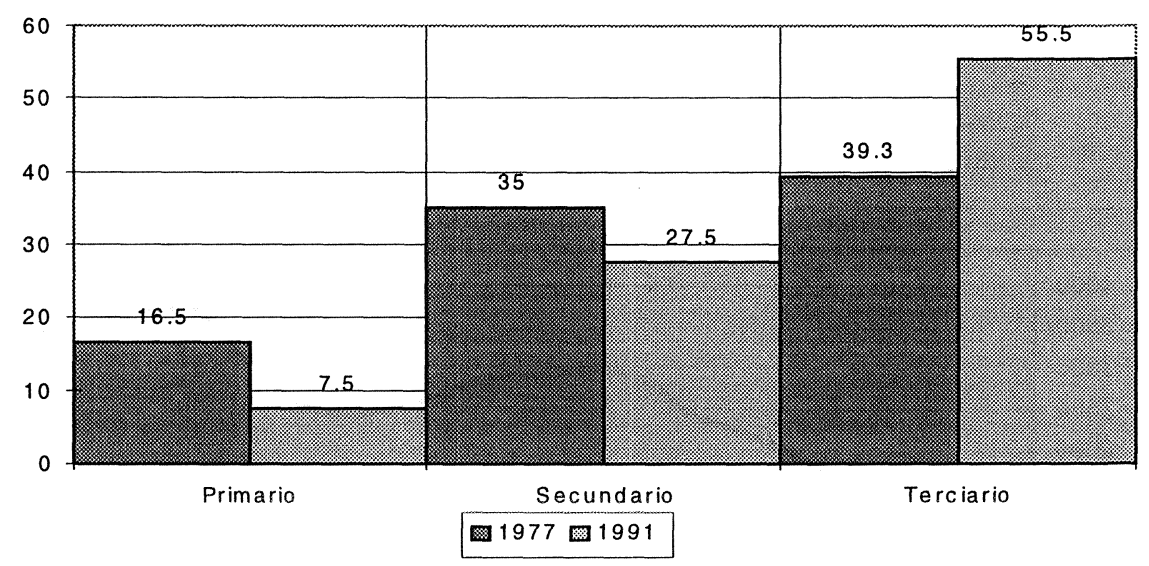

del PIB y con un incremento de la inflación, diremos que estamos en un periodo de estanflación. Veamos cómo ha sido la evolución del paro en el territorio español para más tarde ver cómo ha sido la de la Comunidad Valenciana. De igual manera que con la población ocupada, se ha construido un indicador que reseñe los incrementos anuales para así poder hacer una análisis comparado entre la evolución del paro español y el de la Comunidad Valenciana. Sin embargo, y sirva de adelanto, la realidad económica no puede ser explicada únicamente ni por los niveles de paro ni por los de población ocupada. Hay otros factores que se podrían tener en cuenta y que incluso se han pensado para medir el desarrollo económico (Elkan, 1973: cap 2), como por ejemplo el Producto Interior Bruto (PIB). Pero el lector habrá comprobado que no estamos hablando en términos de desarrollo económico, sino de situación económica positiva o negativa.

Evidentemente que el PIB podría entrar también en el modelo de valoración de la situación, pero hemos considerado otro tipo de indicadores que se acercan más a las personas, ya que les afecta de manera directa. Veamos la evolución del paro en España desde 1976.

A continuación se muestra la evolución del paro en la Comunidad Valenciana. La comparación entre ambos puede ser realmente interesante.

Los dos gráficos siguientes, aunque ilustrativos - porque nos permiten ver las evoluciones del número de parados - no nos sirven para comparar. Si bien la proporción del paro valenciano con respecto al total nacional ha oscilado entre el 
$6,08 \%$ y el $10,93 \%$, mínimo y máximo respectivamente y podríamos pensar, haciendo constante la proporción, en un análisis comparado, es mejor que observemos, como hicimos con la población ocupada, los incrementos anuales de los dos paros. Más tarde realizaremos alguna consideración al respecto.

Gráfico 3.

Evolución del paro en España. Miles (1976-1997).

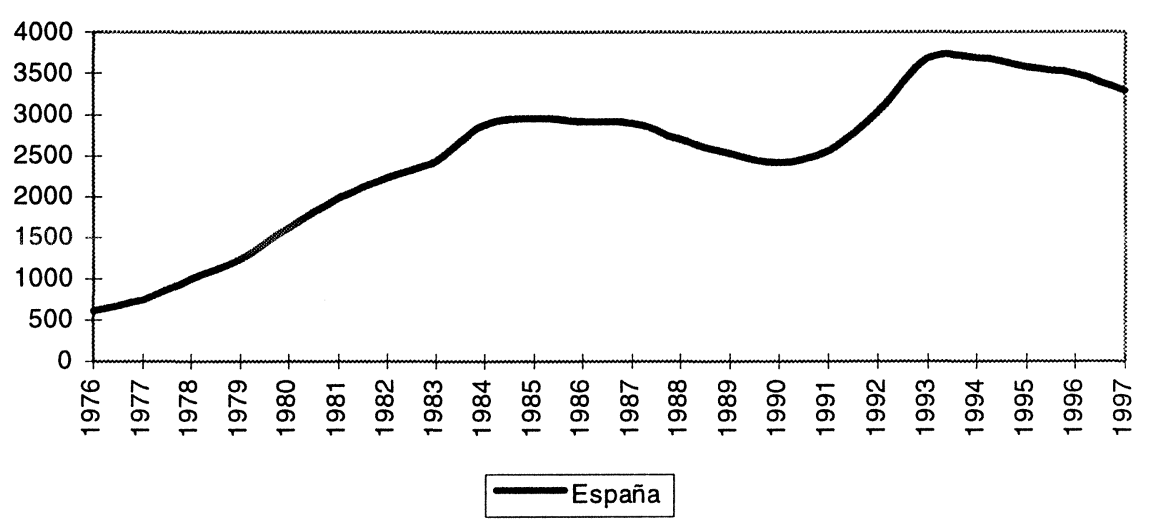

Gráfico 4.

Evolución del paro en la Comunidad Valenciana.

Miles (1976-1997).

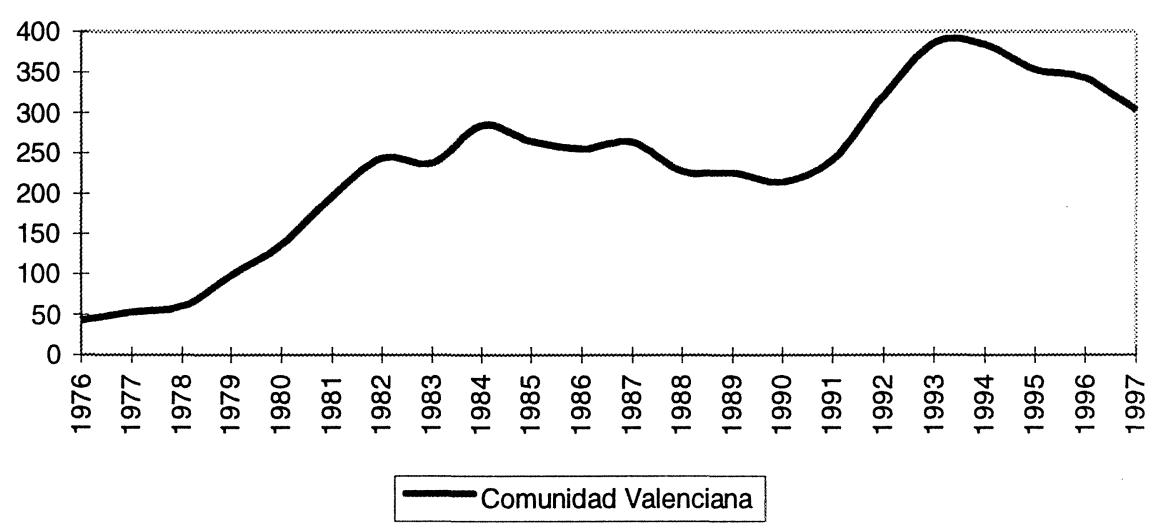


Gráfico 5.

Evolución de los incrementos anuales (\%) del paro. España, Comunidad Valenciana

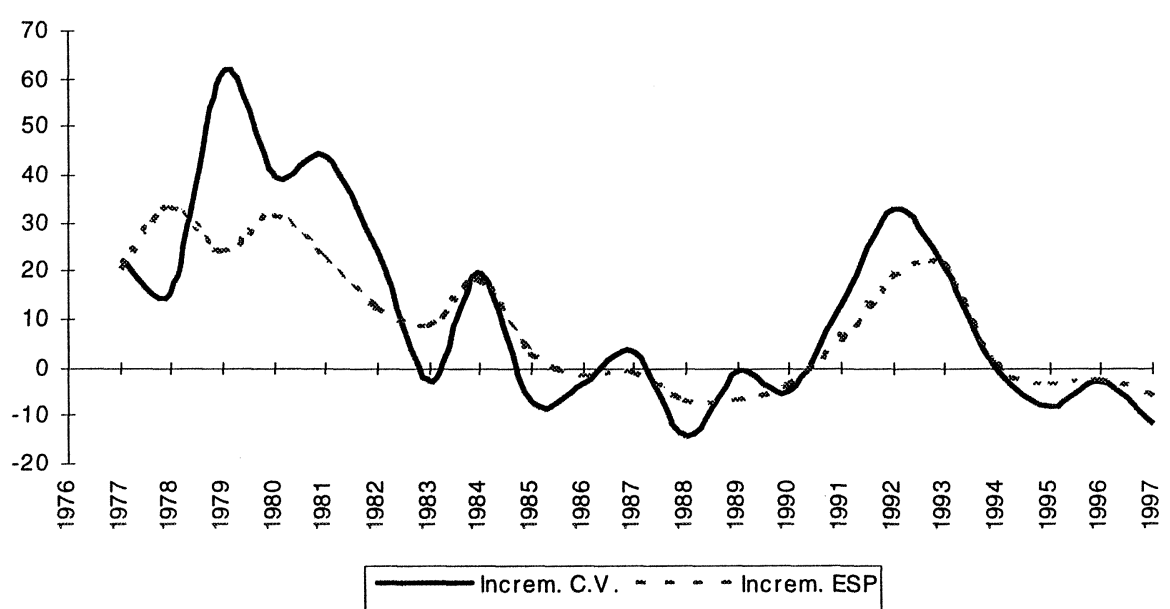

Algunos comentarios se hacen necesarios. Parece que los incrementos del paro en la Comunidad Valenciana son más acentuados que en el del total nacional. También sucede en los decrementos, pero de manera más suave. Varias cosas son importantes:

a) Nuevamente, hay un incremento del paro desde finales de los 80 hasta mediados de ésta década, una estabilización de los incrementos hasta 1990, un incremento rápido en los primeros años de esta década y un descenso moderado hacia 1996.

b) Pero es reseñable que la tendencia, tanto en España como en la Comunidad Valenciana, es a la reducción paulatina de los incrementos anuales de paro. Los incrementos negativos, aunque en números absolutos se mantengan altos y se incrementen positivamente a lo largo de los años, las mejoras con respecto a la situación son más fácilmente observables con este tipo de incrementos anuales. $\mathrm{Y}$ aunque se puede pensar que el paro ha crecido desde 1976 hasta nuestros días, como ha sucedido, el comportamiento interno de este crecimiento en términos absolutos es, probablemente, lo que acabe percibiendo el ciudadano: el diferencial entre una situación pasada reciente (año anterior, trimestre anterior) y la actual.

Antes de pasar al último bloque de indicadores para establecer el ciclo de la situación económica, quisiera presentar el gráfico 6 , en el que se relaciona la tasa 


\section{Gráfico 6.}

Comparación de las tendencias de la tasa de paro y la de inflación en España. (\%) (1977/1996).

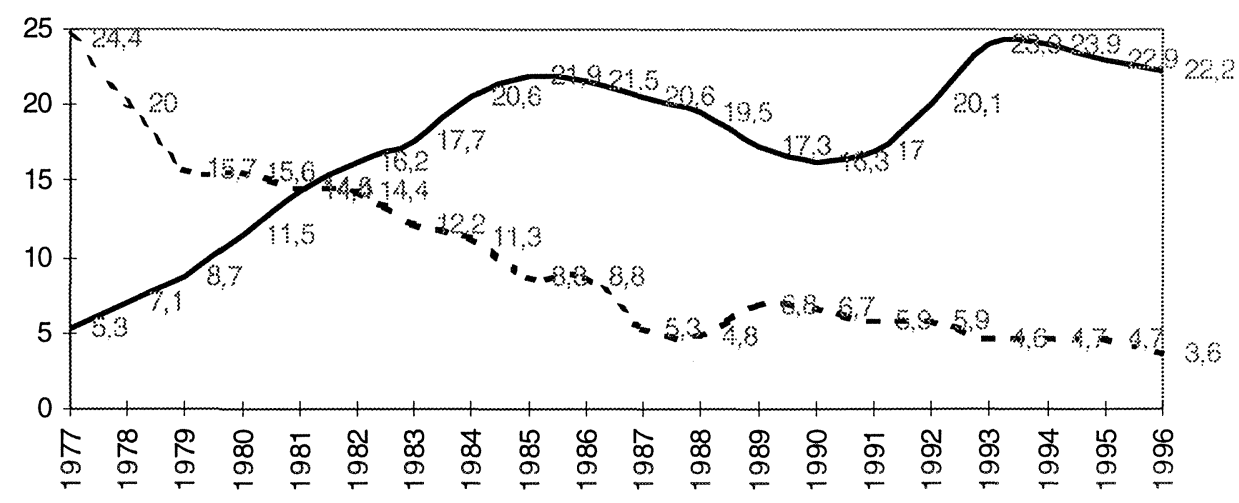

$$
\text { - - - Inflación — Tasa Paro }
$$

de paro en España con la tasa de inflación. Este último elemento nos servirá de manera eficaz para acabar de dilucidar el signo de la tendencia de la situación económica.

Aunque la tasa de paro tiene una tendencia al alza en todo el periodo y se corresponde inversamente con la tendencia de la inflación, posiblemente la tasa de paro inicial esté infraestimada por las condiciones propias de medición durante el franquismo. De esta forma, el proceso de incremento de la tasa de paro hasta 1986 evidencia el fin de un ciclo recesivo. Y a pesar de que la tasa de paro desciende levemente en lo que podría ser la recuperación de los últimos años de la década de los 80 , ésta vuelve a crecer en los años siguientes hasta máximos nunca alcanzados con anterioridad, para iniciar una tendencia descendente en la recuperación de los 90, que continúa hasta nuestros días. El comentario que se desprende de lo anterior no es otro que evidenciar la tendencia ascendente del paro y la descendente de la inflación en forma de logarítmica inversa. El esquema gráfico que resume lo anterior se representa a continuación.

La tendencia es que a grandes incrementos en la tasa de paro en periodos recesivos, no le corresponden decrementos equivalentes en periodos de bonanza, consolidándose la tendencia positiva. Y aunque en la actualidad la tasa de paro está descendiendo por circunstancias más cercanas a la flexibilización del 


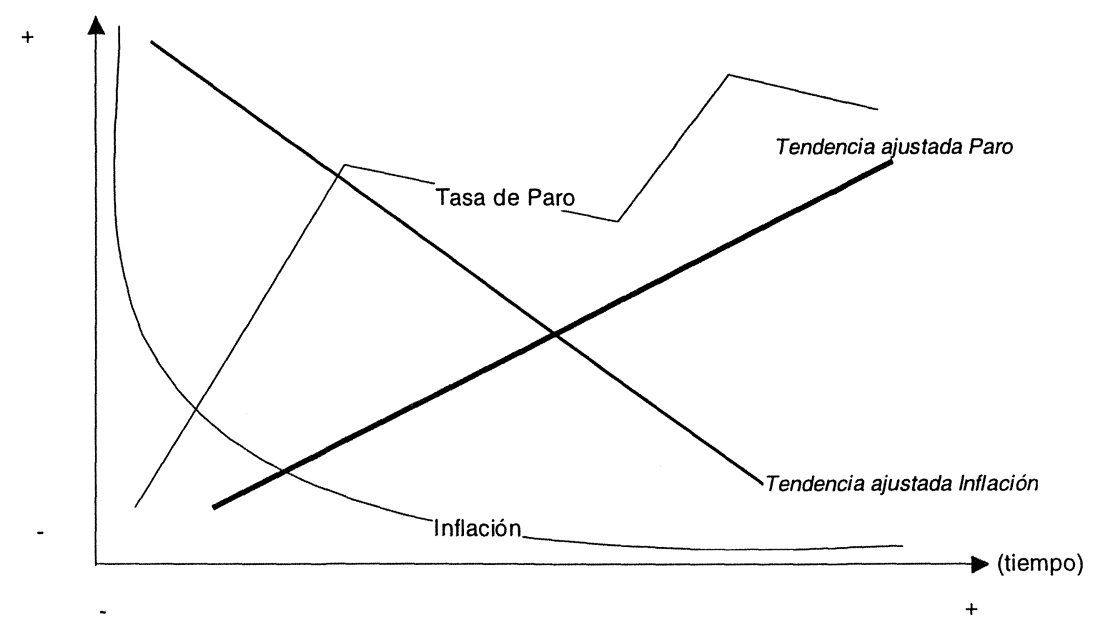

mercado laboral y a la precarización del empleo, si la tendencia continúa en su signo, en un plazo de unos años esta tasa remontará significativamente. Por el contrario, parece que la tendencia de la tasa de inflación en España sigue derroteros diferentes a los anteriormente expuestos.

\section{Creación y destrucción de empleo: último indicador}

Como último dato antes de establecer las consideraciones finales sobre la evolución de la situación económica desde las estadísticas, vamos a tomar la creación y la destrucción de empleo, ahora únicamente para la Comunidad Valenciana. Muy relacionados con las dos variables que hemos visto con anterioridad, la creación de empleo y su antónimo se presentan como un buen indicador de la salud, valga el símil, de la economía, en cuanto ésta afecta a las personas.

La tabla 3 nos viene a decir que por cada puesto nuevo de trabajo que se crea, desde 1980 hasta 1990, se destruye una media de 1,84 puestos de trabajo. La media de esta ratio nos puede servir para establecer una gradiente de mucha destrucción de empleo (cuando los valores de la ratio estén por encima de ésta) y de menor destrucción de empleo (con respecto a la media). Esta diferencia de medias puesta en un eje temporal, nos permite observar con un criterio más comparativo la creación y la destrucción de empleo.

Como se muestra en el gráfico 7, hay periodos de mayor destrucción de empleo, y otros de menor. Como era de suponer, esos periodos y los signos de la relación coinciden con los establecidos para la evolución de los otros dos indicadores que hemos visto con anterioridad. 
Tabla 3.

Destrucción y creación de empleo en la Comunidad Valenciana.

\begin{tabular}{ccccc}
\hline Años & Colocaciones & $\begin{array}{c}\text { Puestos } \\
\text { de trabajo } \\
\text { nuevos }\end{array}$ & Despidos & $\begin{array}{c}\text { Ratio Despidos/ } \\
\text { Trabajos } \\
\text { nuevos }\end{array}$ \\
\hline 1980 & 121708 & 7954 & 20902 & 2,63 \\
1981 & 118559 & 24511 & 46937 & 1,91 \\
1982 & 123909 & 19016 & 41831 & 2,20 \\
1983 & 134576 & 14376 & 39466 & 2,75 \\
1984 & 166718 & 19139 & 38406 & 2,01 \\
1985 & 252210 & 21140 & 36381 & 1,72 \\
1986 & 292627 & 21013 & 31684 & 1,51 \\
1987 & 342238 & 17956 & 28065 & 1,56 \\
1988 & 431136 & 23579 & 31051 & 1,32 \\
1989 & 456589 & 29632 & 27190 & 0,92 \\
1990 & 517785 & 18626 & 31652 & 1,70 \\
& & & Media & 1,84 \\
\hline
\end{tabular}

Fuente: Beneyto,1992.

Gráfico 7.

Creación y destrucción de empleo.

Diferencias de medias para la Comunidad Valenciana.

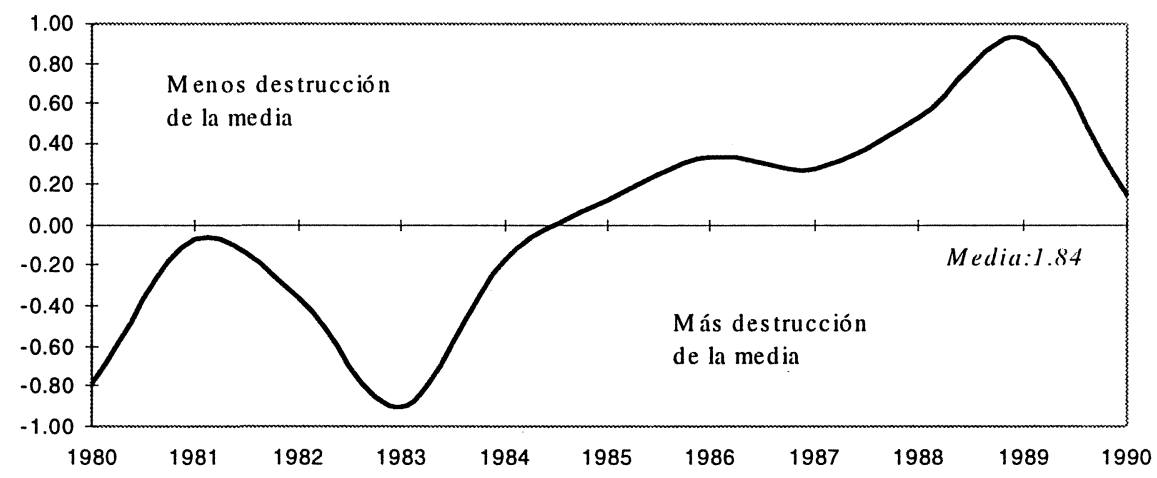


Las conclusiones que podemos alcanzar desde el punto de vista de la situación económica y a la luz de los distintos indicadores escogidos, son que el signo de ésta (positivo, negativo) se establece en distintos periodos desde finales del franquismo hasta nuestros días, como se puede ver en el Gráfico 8. Pero es justo decir que si bien se pueden establecer ciclos en los veinte años que estamos analizando (ciclos de entre cinco y seis años), no está de más enmarcar estas tendencias cíclicas en el marco de un ciclo económico más amplio, que abarca casi medio siglo. Tampoco es posible desligar los distintos ciclos económicos locales de los globales y el sentido de ir a remolque de aquellos hechos que desde los centros económicos se suceden. Este es el caso de la situación económica de la Comunidad Valenciana desde mi punto de vista. Por un lado, la economía valenciana ha sufrido las consecuencias de la no previsión de la crisis económica global de 1973/77 que, por causas políticas, no fue advertida a tiempo en España; y por otro lado, las recuperaciones y las recaídas han estado muy ligadas a las peculiaridades del sistema económico valenciano, del tejido de empresas y de la cultura empresarial.

Gráfico 8.

La situación económica de la Comunidad Valenciana en el tiempo (1976-1997).

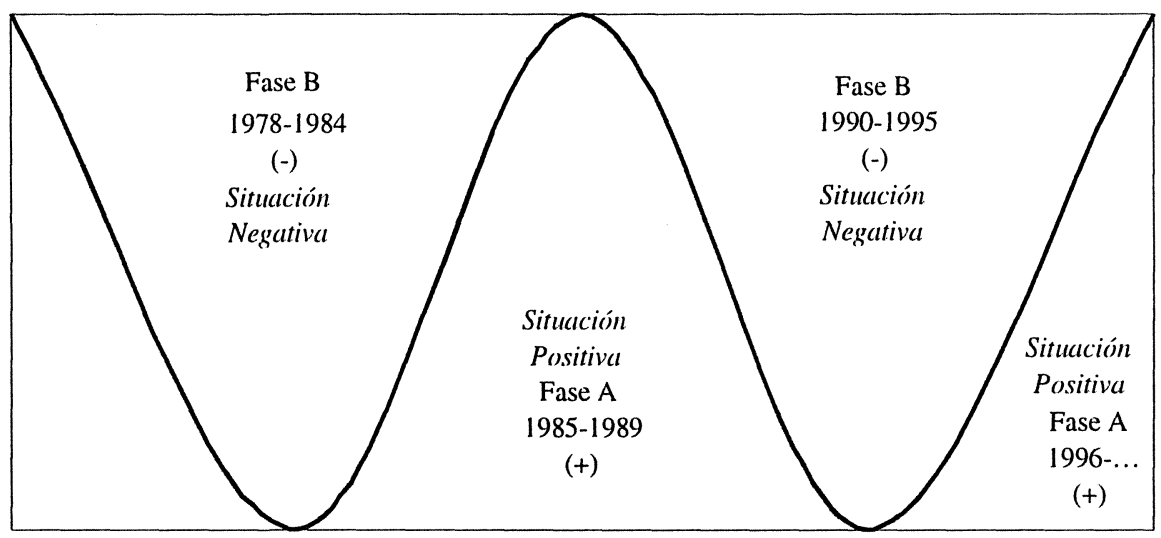




\section{SITUACIÓN GENERAL Y SITUACIÓN ECONÓMICA EN LA COMU- NIDAD VALENCIANA, SEGÚN LOS VALENCIANOS}

\section{La situación general de la Comunidad Valenciana}

Imaginemos por un momento que reflexionamos sobre la situación general de la Comunidad Valenciana. Al margen de ser algo lo suficientemente abstracto como para pronunciarse, cada uno de nosotros responderá A o B por cuestiones personales y quizá circunstanciales y no atendiendo al criterio de supuesta globalidad implícita en la pregunta. Tal vez si nos preguntasen cómo nos va la vida en general, nuestras respuestas estarían más ajustadas a la cuestión. Probablemente, cuando al entrevistado se le pregunta por la situación general de la Comunidad Valenciana piensa en su situación personal y extrapola. Veamos qué piensa el ciudadano de la Comunidad sobre la situación general de ésta, desde una perspectiva temporal que abarca desde 1988 hasta 1997.

Si agrupamos categorías en el supuesto siguiente y formamos otras nuevas que sean Situación General Positiva (formada por las opiniones muy buena y buena) y Situación General Negativa (formada por las opiniones mala y muy mala), dejando la Situación Regular sin transformar, podemos hacernos una imagen sobre la evolución de la percepción de la situación general de la Comunidad Valenciana dentro de los ejes positivo y negativo (y regular, como punto intermedio y un poco cajón de sastre). La tendencia, en estos 10 años, aun con el salto de 1992 a 1997, es de un incremento de la visión positiva desde 1990, invirtiéndose la tendencia hasta los niveles de 1988 en 1997. Como se muestra en el Gráfico 9,

Tabla 4.

Opinión sobre la situación general (actual) de la Comunidad Valenciana (1988-1997) (\%)

\begin{tabular}{rrrrrrrrr}
\hline Años & $\begin{array}{c}\text { Muy } \\
\text { Buena }\end{array}$ & Buena & Regular & Mala & $\begin{array}{c}\text { Muy } \\
\text { mala }\end{array}$ & N.S. & N.C. & $\begin{array}{c}N^{\circ} \\
\text { Estudio }\end{array}$ \\
\hline 1988 & 4 & 36 & 42 & 11 & 2 & 4 & 1 & 1754 \\
1990 & 10 & 44 & 38 & 5 & 1 & 2 & & 1857 \\
1991 & 6 & 47 & 38 & 4 & 1 & 3 & 1 & 1907 \\
1992 & 3 & 47 & 40 & 7 & 1 & 2 & & 1988 \\
1997 & 4 & 37 & 42 & 13 & 2 & 1 & & 2241 \\
\hline
\end{tabular}

Fuente: Elaboración propia a partir de los estudios señalados. 
Gráfico 9.

Situación General Positiva y Negativa de la Comunidad Valenciana (1988-1997)

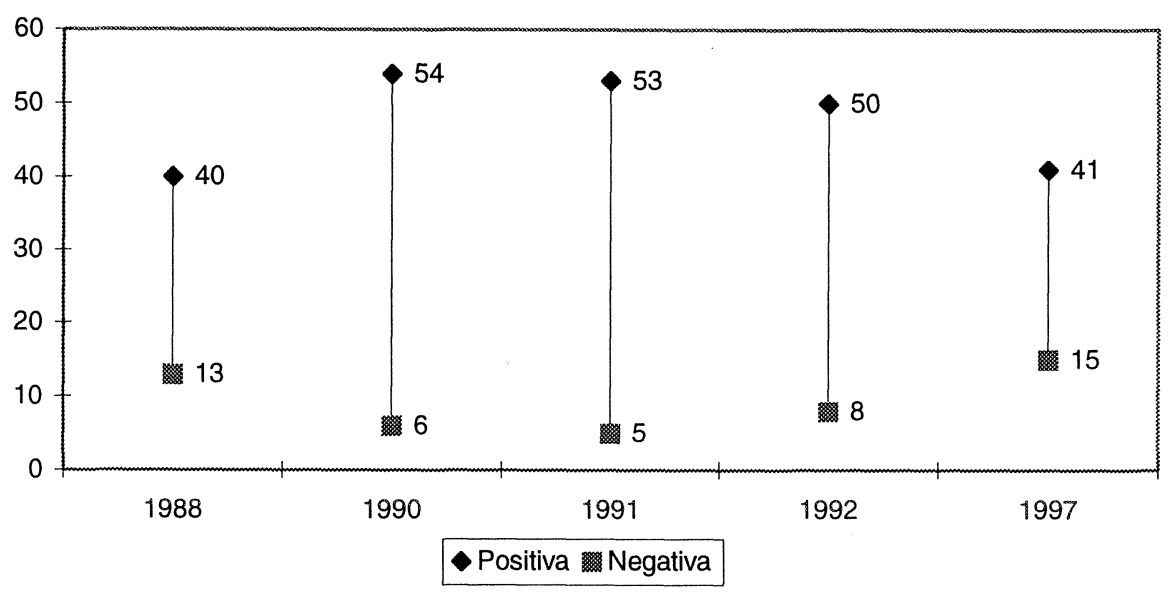

las series "visión positiva de la situación" y su antónima, tienen una relación inversamente proporcional. Más tarde relacionaremos esto con otros aspectos de la realidad social.

Otra cuestión que resulta paradójica en los datos mostrados con anterioridad, es que, en la mayoría de los intervalos temporales, la percepción «positiva» de la situación general de la Comunidad Valenciana está por encima de la "regular", que en un principio podría estar inflada por lo abstracto de la pregunta. Sin embargo, parece que el efecto es el contrario: se tiende a valorar la situación general de manera más positiva de lo que realmente es. Si observamos las estadísticas sobre el paro, comprobamos precisamente que es desde 1990 hasta 1995 cuando más altas cuotas se alcanzan.

Es posible también realizar una análisis retrospectivo y prospectivo sobre la situación general de la Comunidad Valenciana según las opiniones de sus ciudadanos. Podemos así comprobar si los valencianos son especialmente optimistas con respecto al presente y cuál es su opinión acerca de la evolución futura. Digamos a priori que cualquier tiempo pasado fue peor (hablamos de 40 años de dictadura, de una recesión económica importante y de un panorama político por consolidar tras la muerte de Franco) y, de esta manera, las esperanzas puestas en el futuro deben dar como resultado una percepción de la situación general futura más próxima a los deseos que a la realidad objetiva. Veamos los datos de ambas cuestiones. 
Por un lado, visión retrospectiva sobre la situación general de la Comunidad Valenciana con una visión de 4 años hacia atrás (ver tabla 5). Para los datos de 1988 se hace referencia a la situación comparada entre ese año y 1984. Para 1995, por ejemplo, hay que interpretar los resultados como comparativos de la situación de 1991 y la de 1995.

Tabla 5.

Visión retrospectiva (4 años) de la situación general de la Comunidad Valenciana (\%).

\begin{tabular}{ccccccccc}
\hline Años & $\begin{array}{c}\text { Mucho } \\
\text { mejor }\end{array}$ & $\begin{array}{c}\text { Mucho } \\
\text { mejor }\end{array}$ & $\begin{array}{c}\text { ho } \\
\text { hambiado } \\
\text { campeorado } \\
\text { algo }\end{array}$ & $\begin{array}{c}\text { Ha } \\
\text { empeorado } \\
\text { algo }\end{array}$ & N.S. & N.C. & $\begin{array}{c}\text { N }^{\text {em }} \\
\text { Estudio }\end{array}$ \\
\hline 1988 & 5 & 52 & 27 & 10 & 2 & 4 & & 1754 \\
1990 & 10 & 48 & 26 & 10 & 2 & 3 & 1 & 1857 \\
1991 & 7 & 45 & 30 & 12 & 2 & 4 & 1907 \\
1992 & 5 & 44 & 31 & 14 & 1 & 4 & 1 & 1988 \\
1995 & 3 & 29 & 35 & 28 & 3 & 2 & 2145 \\
\hline
\end{tabular}

Fuente: Elaboración propia a partir de los estudios señalados.

Sí que parece que, con respecto al pasado, hay una percepción negativa si se compara con el hoy de las encuestas, excepto en 1995, en el que los porcentajes digamos que se equiparan en las distintas categorías.

Gráfico 10.

Representación gráfica de la visión retrospectiva sobre la situación general de la Comunidad Valenciana (1988).

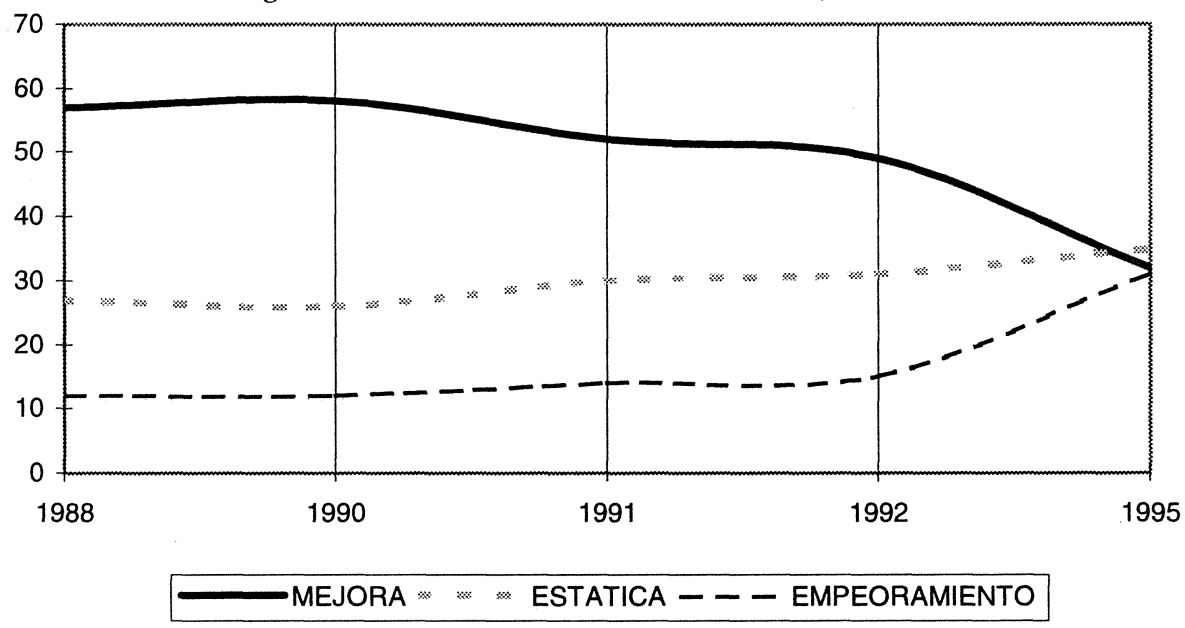


Con respecto a la situación prospectiva (4 años vista) también se puede presuponer un optimismo demasiado generoso. Veamos los datos.

Tabla 6.

Visión prospectiva (4 años) de la situación general de la Comunidad Valenciana (\%).

\begin{tabular}{cccccccc}
\hline Años & $\begin{array}{c}\text { Mejorará } \\
\text { mucho }\end{array}$ & $\begin{array}{c}\text { Mejorará } \\
\text { bastante }\end{array}$ & $\begin{array}{c}\text { Ni } \\
\text { ni ejorará }\end{array}$ & $\begin{array}{c}\text { Empeorará } \\
\text { bastante }\end{array}$ & $\begin{array}{c}\text { Empeorará } \\
\text { mucho }\end{array}$ & N.S & $\begin{array}{c}\text { N }^{\mathbf{0}} \\
\text { Estudio }\end{array}$ \\
\hline 1988 & 8 & 48 & 18 & 6 & 1 & 19 & 1754 \\
1990 & 9 & 44 & 24 & 5 & 1 & 17 & 1857 \\
1991 & 5 & 38 & 25 & 6 & 1 & 25 & 1907 \\
1992 & 2 & 38 & 30 & 9 & 1 & 20 & 1988 \\
\hline
\end{tabular}

Fuente: Elaboración propia a partir de los estudios señalados.

Los datos anteriores muestran cierta visión positiva para con el futuro inmediato, excepto en la encuesta correspondiente a 1992, en la que el futuro no parece contemplarse de manera tan positiva como en años anteriores, tal vez porque en 1992 ya la crisis económica empezaba a notarse de manera más evidente. Pero la clave de esta tabla está en los No sabe, porcentaje realmente alto y que podría dar el signo contrario a los datos si se posicionaran.

Gráfico 11.

Visión prospectiva de la situación general de la Comunidad Valenciana, para los próximos años (1988).

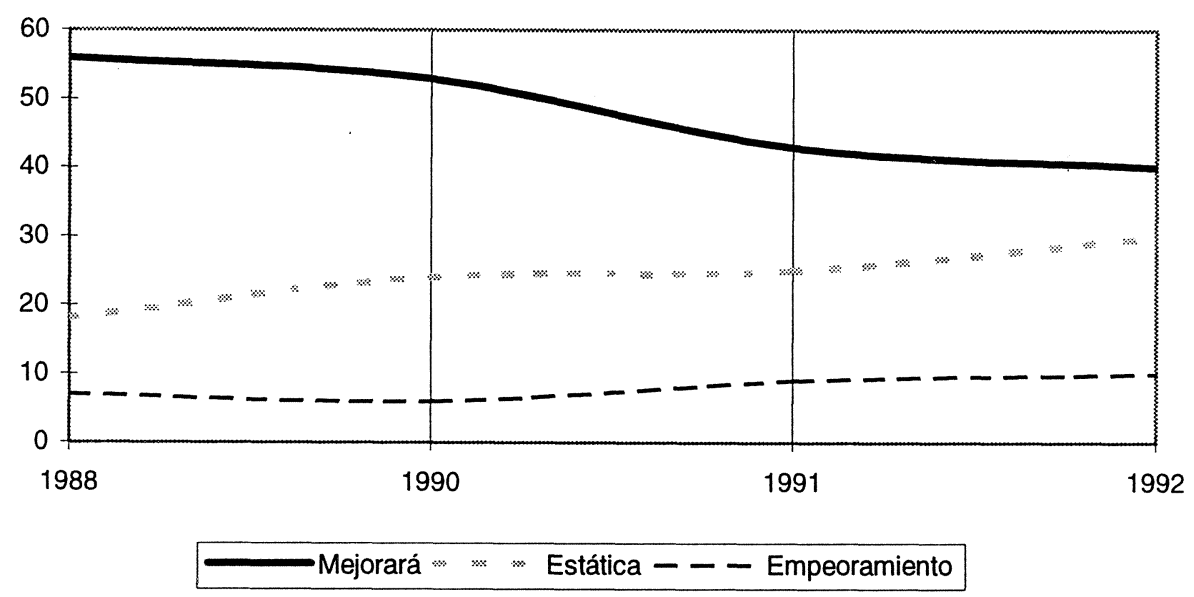


Al margen de la percepción sobre la situación general, también podemos establecer una serie de datos históricos con los problemas que más preocupan a los valencianos. En las encuestas del CIS se suele preguntar directamente así y se deja al entrevistado que responda de manera espontánea. Es curioso, como se verá a continuación, que los tres problemas que más preocupan a los valencianos son siempre los mismos, aunque con variaciones porcentuales, evidentemente: paro, delincuencia (inseguridad ciudadana), el problema de las drogas y la crisis económica en clara consonancia con los ciclos económicos. En el Gráfico 12 se muestra la evolución temporal de estas consideraciones generales sobre los principales problemas de la Comunidad Valenciana. Más tarde, en la tabla 7 aparecen reflejados los principales problemas que el valenciano ha enunciado como los más importantes desde 1984 hasta 1997 en porcentajes.

Como se observa en el gráfico 12 , la principal preocupación de los valencianos en el tiempo es, aunque con oscilaciones pero claramente por encima del resto de las otras, el paro. A partir de 1986, y así se mantiene hasta 1997, el problema de las drogas es el segundo de las situaciones que se percibe como más problemática entre los ciudadanos valencianos. Es paradójico que uno de los problemas fundamentales, como es la crisis económica, que podría servirnos como explicación a muchos de los otros problemas, está muy por debajo, comparativamente hablando, de las situaciones percibidas como problemáticas por los valencianos desde 1984.

Gráfico 12.

Evolución temporal de los principales problemas observados por los valencianos (1984-1996)

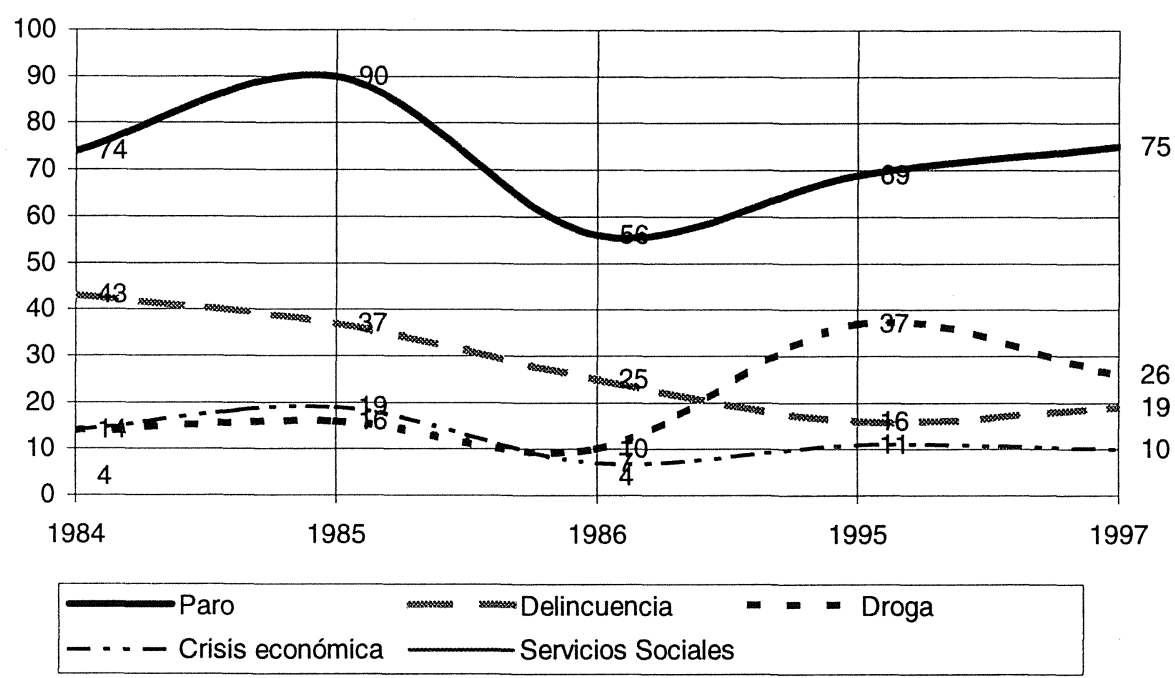


Tabla 7.

Principales problemas que tiene la Comunidad Valenciana. El número de respuestas varía en función de los estudios. Los porcentajes se calculan en función de los casos.

\begin{tabular}{lrrrrr}
\hline Problemas & 1984 & 1985 & 1986 & 1995 & 1997 \\
\hline El agua & 4 & 2 & 4 & $\underline{31}$ & 6 \\
Paro & 74 & 90 & 56 & 69 & 75 \\
Delincuencia & 43 & 37 & 25 & 16 & 19 \\
Droga & 14 & 16 & 10 & 37 & 26 \\
Crisis económica & 14 & 19 & 7 & 11 & 10 \\
Educación & 4 & 5 & 5 & & \\
Campo, agricultura & 12 & 7 & 7 & & 10 \\
Servicios Sociales & 4 & & 4 & & 10 \\
Otros & 7 & & 18 & & \\
NC & 16 & & & & \\
\hline
\end{tabular}

Los huecos que aparecen sin dígitos es porque no hay datos para esos años. La tabla anterior evidencia dos cosas, fundamentalmente. 1) Que hay una serie de problemas que son percibidos de manera que se consideran como algo estructural, como problemas intrínsecos y constantes en el sistema social (son los marcados en cursiva) y que fluctúan según los periodos. Hay que destacar el caso de la crisis económica como problema, que es considerado siempre como tal, pero que se marca con los ciclos económicos depresivos y se valora menos como problema en los periodos de recuperación. 2) Que hay otros problemas que aparecen con una clara incidencia en momentos puntuales; son fenómenos más coyunturales (sequía, conflictividad agrícola) que en el momento que se capta la foto que supone la encuesta, se reseñan de forma evidente.

\section{La situación económica vista por los valencianos. El descifrado de las mag- nitudes económicas}

Es posible establecer ciclos económicos atendiendo al signo de la economía y a través de la conjunción de distintos indicadores. A la vez que se suceden los hechos estadísticos se realizan encuestas de opinión en las que se podría pensar que aparecen reflejados cómo son percibidos los distintos aspectos de la realidad y su interpretación. Incluimos aquí los hechos económicos o la situación económica en general y su signo. 
A través de los cuestionarios del CIS podemos construir una serie de datos históricos sobre la opinión que les merece a los valencianos la situación económica que están atravesando. Podemos remontarnos hasta 1984 (final de la recesión que empezó por allá en 1978) y finalizar en el último estudio realizado por el CIS cuyo ámbito es la Comunidad Valenciana y que incluye la pregunta sobre valoración de la situación económica (ya en 1997).

Tabla 8.

Situación económica de la Comunidad Valenciana (\%)

\begin{tabular}{lcccccccc}
\hline Fecha & $\begin{array}{c}\text { Muy } \\
\text { Buena }\end{array}$ & Buena & Regular & Mala & $\begin{array}{c}\text { Muy } \\
\text { Mala }\end{array}$ & NS & NC & $\begin{array}{c}N^{\circ} \\
\text { Estudio }\end{array}$ \\
\hline 1984 & 0 & 15 & 48 & 26 & 4 & 7 & 0 & 1437 \\
1985 & 0 & 15 & 42 & 26 & 3 & 9 & 5 & 1458 \\
1985 & 1 & 20 & 49 & 16 & 2 & 12 & 0 & 1490 \\
1986 & 2 & 33 & 48 & 9 & 1 & 6 & 0 & 1532 \\
1987 & 1 & 21 & 47 & 17 & 2 & 11 & 1 & 1556 \\
1994 & 1 & 18 & 43 & 30 & 6 & 2 & 1 & 2094 \\
1995 & 1 & 17 & 39 & 30 & 11 & 2 & 0 & 2145 \\
1997 & 1 & 41 & 43 & 10 & 1 & 4 & 0 & 2241 \\
\hline
\end{tabular}

Fuente: Elaboración propia a partir de los estudios señalados.

Poniendo a un lado los saltos temporales en las series (cuestión que nos ha resultado imposible solucionar por la sencilla razón de la inexistencia de datos) y que dificultan el análisis, podemos hacer un comentario general al respecto del cuadro anterior. Digamos que la categoría central que viene a decir que la situación económica es "regular" es la que más \% acumula en todos los años. Esto se explica por la propia naturaleza de las encuestas de opinión y las reacciones de los entrevistados a preguntas en las que se les permite posicionarse en el centro de las opciones. Dejemos de momento las categorías "buena" y "mala" para centrarnos en los extremos. Si los datos siguieran la distribución Normal, los extremos concentrarían el menor volumen de casos, pero sin diferenciarse mucho en sus totales. Esto parece que no ocurre entre situación económica "muy buena" y "muy mala". Puestos a elegir extremos, parece que el criterio es inflar las situaciones más negativas de la economía. Esto se puede ver bien con el gráfico que se muestra a continuación y que relaciona las distribuciones temporales de la situación económica vista como muy buena o muy mala.

Podemos hacer una agrupación de categorías como hicimos para la percepción de la situación general y establecer un signo general de la evolución de la situación económica para los valencianos. Al colapsar las categorías "muy bue- 
Gráfico 13.

Diferencias entre situación económica "Muy Buena" y "Muy Mala"

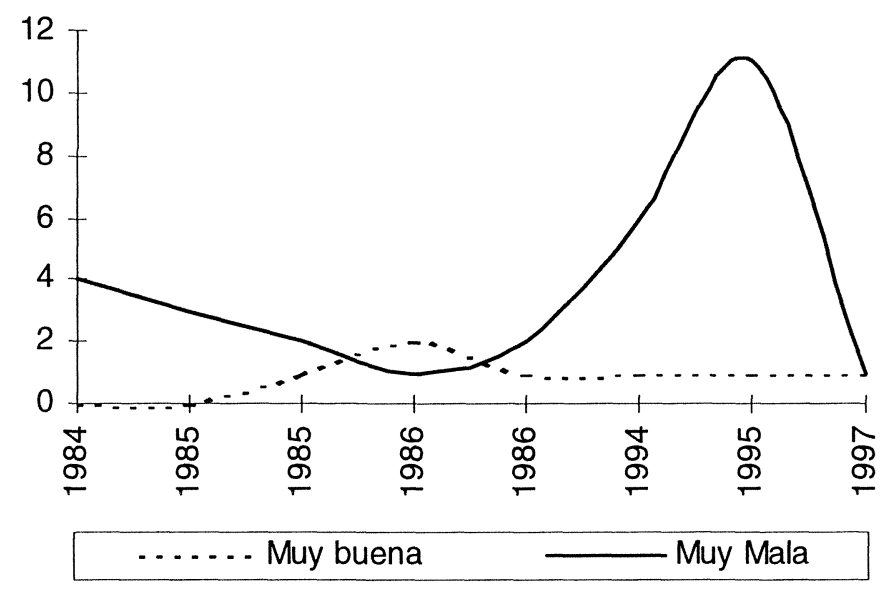

na" y "buena" en una sola y atribuirles la cualidad de "visión positiva de la economía" y hacer lo propio con el polo opuesto bajo el nombre de "visión negativa de la economía", podemos representarnos la situación económica dentro de los ejes "Situación Positiva" y "Situación Negativa".

Si dispusiéramos de estudios de periodicidad anual en los que se preguntara la percepción de la situación económica, podríamos decir que se calcaría la distribución en el tiempo de esta pregunta con el ciclo económico que se desprende de las estadísticas económicas. Aun no disponiendo de los datos anuales procedentes de encuesta, los resultados que se muestran una vez atribuido signo a la situación económica, aparecen en el Gráfico 14, que casi es idéntica al Gráfico 8 en el que exponíamos los distintos ciclos económicos en el tiempo en la Comunidad Valenciana.

Los signos (+) y (-) denotan el tipo de momento en el que se encuentra el ciclo económico. Si el periodo está marcado por el signo (-), es un periodo recesivo, y cuando aparece señalado con el signo (+) todo lo contrario. Extrapolado al lenguaje de los ciclos económicos de larga duración, los (-) significan fase B del ciclo y los (+) fase A. como se puede observar en el gráfico, podría asegurarse que los entrevistados valencianos perciben e interpretan de manera clara (calificando como positiva o negativa la situación económica) lo que probablemente esté sucediendo en otras esferas más complejas. 
Gráfico 14.

Situación Económica Positiva y Negativa de la Comunidad Valenciana.

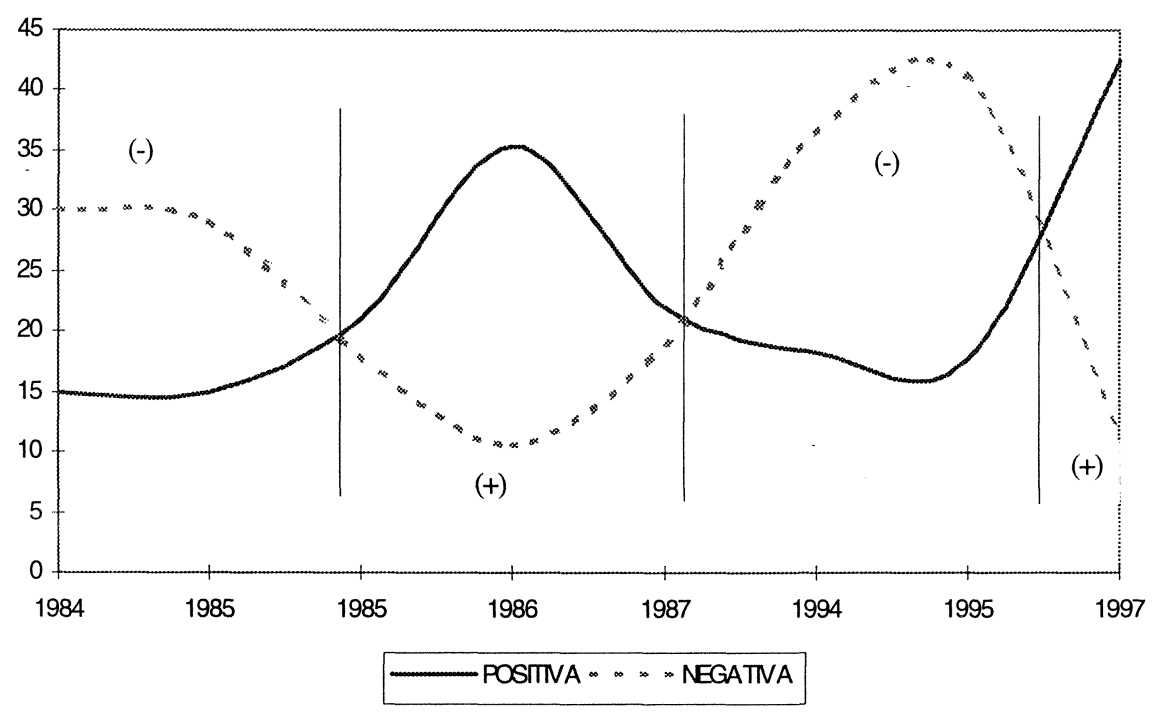

Un análisis interesante que nos podría señalar la validez relativa de estas percepciones sería poder comprobar la opinión comparada entre la situación económica de la Comunidad Valenciana y la del resto de regiones. Desde mi punto de vista, el entrevistado valenciano va a sobrevalorar la situación económica positiva de la Comunidad Valenciana en la comparación con otras regiones. Quizá la pregunta que da lugar a la serie de la Tabla 9 esté mal formulada desde el momento en que no se establecen exactamente qué regiones entran en el segundo término de la comparación. Evidentemente la Comunidad Valenciana parece que económicamente tiene una situación más positiva que Extremadura, pero mucho más negativa si se compara con Cataluña, por ejemplo. De todas maneras, es una buena referencia saber qué piensan los valencianos con respecto a la situación de la economía de su región comparada con otras.

Hay un fenómeno curioso en los datos presentados arriba. A partir de 1990 cambia la percepción sobre la situación económica en la Comunidad Valenciana y las otras regiones. Esto coincide con dos cosas, fundamentalmente: 1) Con las fases A y B del ciclo económico: en la A se tiende a pensar que la situación de la Comunidad es más o menos similar a la del resto de España y en la fase B ocurre al contrario; y 2) con el paulatino descenso de los que no saben dar un veredicto comparado, que es probable que también influya en el cambio de las opiniones. 
Tabla 9.

Evolución de la situación económica de la Comunidad

Valenciana comparada con el resto de regiones (\%)

\begin{tabular}{lcccccc}
\hline Fecha & Mejor & Igual & Peor & N.S & N.C & $\begin{array}{c}\mathrm{N}^{\circ} \\
\text { estudio }\end{array}$ \\
\hline 1984 & 31 & 43 & 4 & 21 & 1 & 1414 \\
1985 & 27 & 48 & 7 & 17 & 1 & 1437 \\
1990 & 53 & 30 & 7 & 9 & 1 & 1857 \\
1991 & 43 & 34 & 10 & 10 & 1 & 1907 \\
1992 & 54 & 35 & 7 & 4 & & 1988 \\
\hline
\end{tabular}

Fuente: Elaboración propia a partir de los estudios señalados.

Gráfico 15.

Evolución de la situación económica de la Comunidad

Valenciana comparada con el resto de regiones (\%)

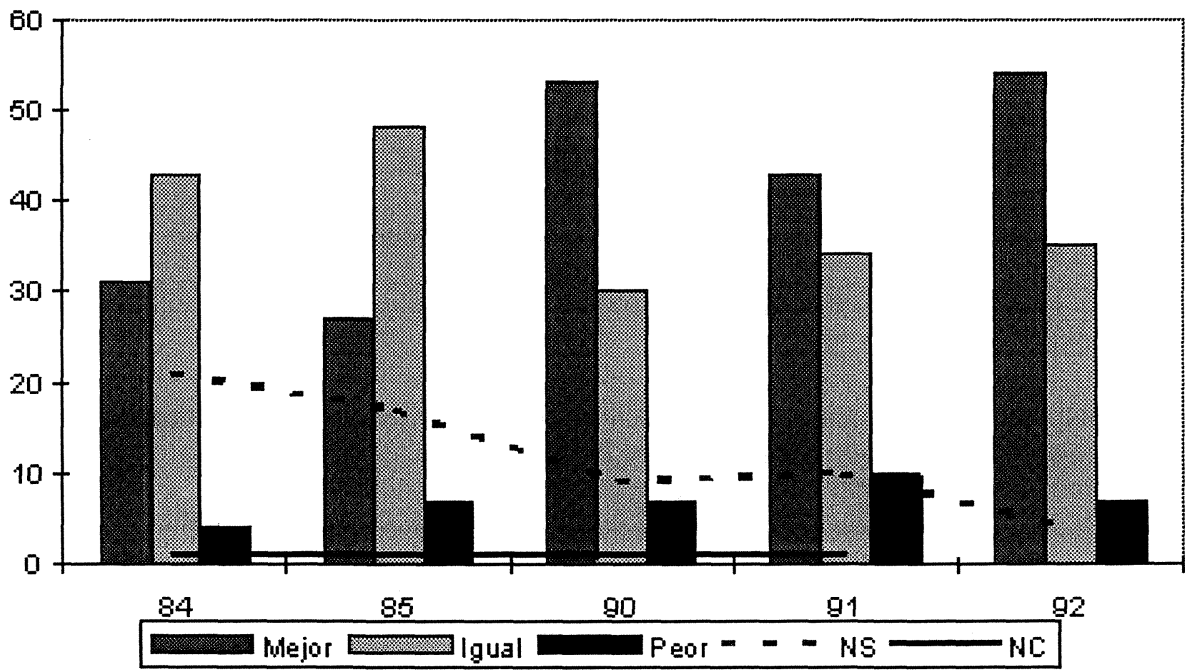




\section{CONCLUSIONES}

Los ciclos estadísticos y los de opinión pública para cuestiones como la situación económica parece que coinciden de manera evidente. De todas formas, si atendemos a las dificultades metodológicas que hemos apuntado en páginas anteriores, es complicado afirmar que exista una coincidencia en los ciclos. No nos preocupa, sin embargo, ya que el objetivo precisamente de este trabajo es otro.

Para concluir, es claro que diferentes tipos de datos ofrecen diferentes visiones de una realidad social determinada. Pero no son visiones excluyentes, sino complementarias. Ciclos estadísticos para determinar el signo de la economía valenciana matizados por la propia percepción del transcurso de los fenómenos económicos por los valencianos en el tiempo, era el ejemplo que planteábamos. El problema, más que la construcción que ya hemos dicho que es prácticamente imposible para el caso de los datos de opinión pública de los que en la actualidad disponemos, es un problema de interpretación, y también de análisis comparado. Aun así, invitamos al lector a plantear las investigaciones presentes y futuras en términos longitudinales, utilizando los ciclos como una herramienta más, en un intento integrador de diferentes perspectivas en las que también entraría, cómo no, el falso debate cuantitativo vs cualitativo.

\section{BIBLIOGRAFÍA}

ALONSO, L.E. (1998), La mirada cualitativa en Sociología, Fundamentos, Madrid.

AMIN, S. (1997), Capitalism in the age of globalization: the management of contemporary society, Zed books, London.

BELL, D. (1973), The coming of post-industrial society, Basic Books, New York.

BENEYTO, P.J. (1992), "Los sindicatos ante la crisis y la renovación", en García Ferrando, M. (Coord) (1992), La Sociedad Valenciana de los 90, pp. 96-128, Alfons el Magnànim, Valencia.

CAÏS, J. (1997), Metodología del análisis comparativo, CIS, Madrid.

CONDE LÓPEZ, F.J. y S. GONZÁLEZ FERNÁNDEZ (1998), Indicadores económicos, Pirámide, Madrid.

DE MIGUEL, A. (1986), España cíclica. Ciclos económicos y generaciones demográficas en la sociedad española contemporánea, Banco Exterior, Madrid.

ELKAN, W. (1973), Introducción a la teoría económica del desarrollo, Alianza, Madrid.

EPSTEIN, P. (1999), «Wesley Mitchell's grand dessing and its critics: the theory and measurement of business cycles», en Journal of Economic Issues, 33, vol. 3. pp. 525-553. 
EVANS, G.W., S. HONKAPOHJA y P. ROMER (1998), "Growth Cycles", American Economic Review, Vol. 88, pp. 495-515.

FONTELA MONTES, E. (1997), Los ciclos económicos en la economía moderna, Biblioteca Nueva, Madrid.

GALTUNG, J. (1995), Investigaciones teóricas, Tecnos, Madrid.

GONZÁLEZ RÍO, M.J. (1997), Metodología de la investigación social, Aguaclara, Alicante.

HIRSCHMAN, A.O. (1984), De la economía a la política y más allá. Ensayos de penetración y superación de fronteras, F.C.E., México.

(1999), Las pasiones y los intereses: argumentos políticos en favor del capitalismo previos a su triunfo, Península, Barcelona.

KONDRATIEV, N. (1979), Los ciclos económicos largos: ¿una explicación a la crisis?, AKAL, Madrid.

MADEL, E. (1986), Las ondas largas del desarrollo capitalista mundial, Siglo XXI, Madrid.

REID, B.G. (1998), "Endogenous Elections, Electoral Budget Cycles and Canadian Provincial Governments", Public Choice, Vol 97, pp. 35-48.

SAPIR, A. y K. SEKKAT (1999), «Optimum electoral areas: should Europe accept a single election day?», European Economic Review, nº43, 8, pp. 1595-1619.

SCHUMPETER, J.A. (1939), Business Cycles, McGraw-Hill, Nueva York.

(1982), Historia del análisis económico, Ariel, Barcelona.

RESUMEN. The longitudinal analysis of data is a way to describe and to explain the social processes. Depending on the source of the data statistical cycles and cycles of public opinion can be established. This article proposes the comparison between both types of cycles for the Valencian Region, between 1977 and 1997. This one concludes with a reflection on the importance of the inclusion of the longitudinal perspective in the analysis of the social reality.

E-mail: ma.mateo@ua.es 